\title{
SENSITIVITY OF BRITTLENESS OF THE CONCRETE TO THE PORE STRUCTURE OF THE CEMENT PASTE
}

\author{
Serkan Yatagan \\ Lecturer, Dr., Building Materials Science, Architecture Faculty, Istanbul, Turkey
}

\begin{abstract}
One of the essential factors which affects the performance of the concrete buildings under earthquake loads is the degree of brittleness of the concrete. It is possible to investigate the brittleness directly by dynamic experiments, whereas the static experiments which make it possible to get some numerical values. In this work, the second way is choosen and the brittleness of the concrete is expressed as the ratio between the compressive strength and the tension strength of the concrete (The brittleness index). The relationship between the brittleness, the grading of the aggregate mixture and the pore structure of the cement paste is investigated. The degree of sensitivity of the values determining the brittleness to the pore structure of the cement paste is also determined; then the factors determining the sensitivity correlation constants are investigated. The correlations between properties are strong because their sensitivities to the pore structure of the cement paste are close.
\end{abstract}

Keywords: Brittleness, Correlation Coefficients, Pore Structure

\section{INTRODUCTION}

All concrete properties are related to the inner structure of the cement paste because the properties of the concrete depend on the reactions of the hydration occurring in the cement paste. In the modern engineering, understanding the effect of the inner structure of the cement paste or how the materials of the concrete change the inner structure of the cement paste or the effects of the interface between the cement paste and the aggregates are important. From the past to the present, within the help of the developing technology, the inner structure of the cement paste is continuosly researched. The first researches of the inner structure of the cement paste are the crystallization theory of Le Chatelier and the Michealis' colladial theory [1]. Powers and his friends proved that as a result of the cement hydration, the fibres like Labermant, form in the cement paste and these fibres are in colladial dimension and they have a great inner surface. Also, the structure of these fibres is gel. Besides this gel, in the cement paste, there are calcium hydroxide crystals, the secondary components, unhydrated cement particles and the pores. These pores are surrounded by the gel. Since the size of these pores is capillary, they are called as capillary pores [2]. There are 4 main components of the cement; $\mathrm{C}_{2} \mathrm{~S}, \mathrm{C}_{3} \mathrm{~S}, \mathrm{C}_{3} \mathrm{~A}$ and $\mathrm{C}_{4} \mathrm{AF}$. After the hydration, these components turn into the hydrated components. The hydrated components are C-S-H (Calcium Silicate Hydrate) and $\mathrm{CH}$ (Calcium Silicate). C-S-H supply the binding property of the cement. The inner structure of the cement paste is porous. The pores form as a result of the hydration reactions because of the formed hydrated products. The capillary pores are formed after the hydration when used water evaporates. The capillary porosity depends on the water/cement ratio and the hydration degree. As the hydration degree increases, the more hydrated products are formed and they fill the pores so the numbers of the pores decrease. However, when the water/cement ratio increases, it is impossible that the hydrated products fill the pores because the amount of the water and the numbers of the pores increases, so the formed hydrated products are not enough to fill these pores. The gel pores are in the hydration products and their numbers and the total volume increase within the hydration process. The dimension of the gel pores is smaller than the dimension of the capillary pores. Besides these pores, there are air voids, the dimension of which is smaller. The air voids are formed because of the insufficient settlement of the concrete or some additives which drag air in the concrete. The interface between the cement paste and the aggregate is called as the weakest chain in the concrete. The inner structure of the interface between the cement paste and the aggregate differs from the inner structure of the cement paste. There are various models for the micro structure of the interface. According to Barnes;

1. A film of $\mathrm{CH}$ acculumates vertically on the aggregates.

2. A film of C-S-H particles, like a hair brush, covers the aggregates.

3. Parallel to the aggregate surface, extensive $\mathrm{CH}$ crystals acculumate.

4. At the inteface zone, full volume formation of $\mathrm{CH}$ is seen. According to Zimbelmann [3]; when the cement paste is mixed with water, in a few minutes, the etthrengite needles are formed. $\mathrm{CH}$ crystals vertically cover the etthrengite needles. The thickness of the level of $\mathrm{CH}$ crystals is 2-3 micron. After this level, hegzagonal $\mathrm{CH}$ crystals begin to develop. The dimension of these hegzagonal crystals changes between 10 and 30 micron. At the interface, the porosity is high so the interface is weak and permeable. The thickness of the interface changes between 10 and 50 micron. The interface comprises the huge part of the concrete. There are some ideas for the formation of the interface. During the mixture of the concrete, the aggregate particles are covered by a film of water. When the hydration starts, forming hydration products connect with this film of water so the 
water/cement ratio of the interface is higher than the original water/cement ratio. Aitcin and Mehta proved that the thickness of the loading-unloading curves specify the strength of the interface between the aggregate and the cement paste [4]. The concretes having the same water/cement ratios and different granulumetries give different results. For example, in the experiments, the elasticity modulus and the compressive strength of the granulumetry between A16-B16 are the highest, whereas the granulumetry between $\mathrm{B} 16-\mathrm{C} 16$ is the lowest. The compressive strength results are shown in Fig.1.The increasing thickness of the loading-unloading curves reveal that the bonds of the interface are weak. Also, according to the loading-uploading curves, when the compressive strength increases, the brittleness index increases. With the increasing strength of the concrete, the interface become unporous and homogeneous.

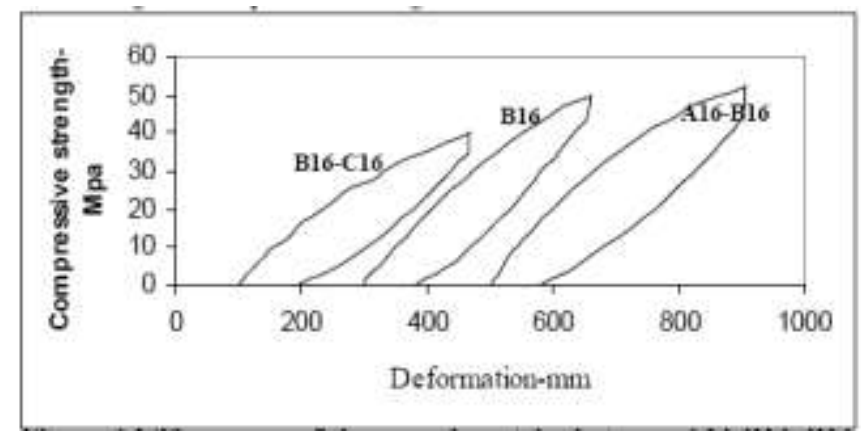

Fig.1-The curves of the granulumetries between A16-B16, B16, B16-C16

In this work, the relationship between the granulumetry of the aggregate mixture, the pore structure of the hardened cement paste and the brittleness of the concrete is investigated. The sensitivity degrees of the values determining the brittleness to the pore structure of the cement paste are determined, the correlations are formed and effects signifying these correlation coefficients are investigated.

\section{EXPERIMENTAL INVESTIGATION}

The brittleness indexes, the compressive and tensile strengths, the moduluses of elasticity and the unit weights of these samples are measured by the experiments made. The correlation constants of these properties are found by the help of these values and then the sensitivity of these properties to the pore structure of the cement paste is investigated.

\subsection{Materials}

The Portland Cement is used and the specific gravity of the Portland Cement is $2,97 \mathrm{gr} / \mathrm{cm}^{3}$. The dosage of the concrete is $350 \mathrm{~kg} / \mathrm{m}^{3}$. The aggregates are broken stone 1 , the sand and the Stone powder. The specific gravity of the aggregates are relatively $2,72 \mathrm{gr} / \mathrm{cm}^{3}, 2,60 \mathrm{gr} / \mathrm{cm}^{3}$ and $2,70 \mathrm{gr} / \mathrm{cm}^{3}$. For the granulumetry between A16-B16, the mixture ratios are $70 \%$ the broken stone $1,20 \%$ the sand and $10 \%$ the stone powder. For B16 granulumetry, the mixture ratios are $65 \%$ the broken stone 1, 25\% the sand and $10 \%$ the stone powder. For the granulumetry between B16-C16, the mixture ratios are $60 \%$ the broken stone $1,30 \%$ the sand and $10 \%$ the stone powder. For every granulumetry, water/cement ratio begins at 0,50 and it is increased by 0,05 to $0,70.15$ types of the concrete are produced. The beginning value of the water/cement ratio is determined with the help of the VeBe experiment. The water/cement ratio of the fresh concrete which gives 7-8 sec in VeBe machine is accepted as the original water/cement ratio.

\subsection{Specimens and Items of Investigation}

After 24 hours, the produced samples are taken out from the moulds and then the samples are held in $23 \pm 2^{\circ} \mathrm{C}$ water for 21 days. At 21.day, the samples are taken out from the water and waited in the room to the 28.day. At 28.day, the compressive strengths of the half of the cylinders $(15 \times 30$ $\mathrm{cm})$ and the splitting strengths of the discs $(6 \times 15 \mathrm{~cm})$ are measured. The cubes $(15 \times 15 \mathrm{~cm})$ are held in $105^{\circ} \mathrm{C}$ oven for 4 hours at 35.day and they are weighed and the dimensions of the cubes are measured in order to calculate the dry unit weight.

The discs are used to measure the splitting strengths. To distribute the load unifomly on the discs, two laths are mutually put on the upper and the lower part of the discs. The elasticity moduluses are calculated within the help of these longitunal deformations. The other half of the cylinders are used to obtain the brittleness indexes. Firstly, the samples are loaded to a certain value and then the samples are unloaded. After unloading, the samples are loaded to the fracture. During this process, longitunal deformations are measured. The certain value is theoratically $80-90 \%$ of the compressive strength of the sample. The graphic is drawn according to these results are shown in Fig.2. In Fig.2, $S_{I}$ is the permanent deformation energy related to the damage and SII is the elastic deformation energy. The $\mathrm{x}$-axis shows the longitunal deformation $(\mathrm{mm})$ and the $y$-axis shows the strength of the samples $(\mathrm{MPa})$. The brittleness index is the ratio between $\mathrm{S}_{\mathrm{I}}$ and $\mathrm{S}_{\mathrm{II}}\left(\mathrm{S}_{\mathrm{II}} / \mathrm{S}_{\mathrm{I}}\right)$.

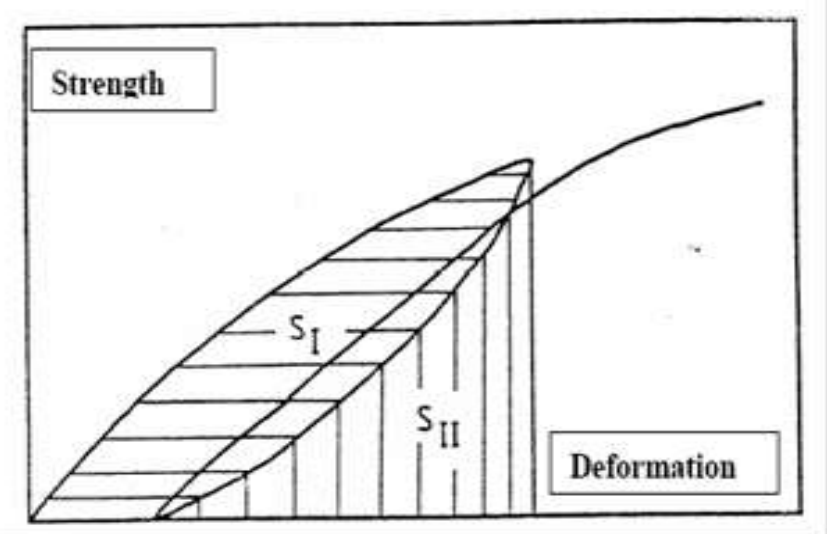

Fig.2-The strength-deformation curves of the repetition loading of the concrete

In Table 1, the brittleness indexes obtained from the graphics of the tests. The brittleness indexes decrease when the water/cement ratio increases. 
Table 1- The brittleness indexes related to the changes of the water/cement ratios

\begin{tabular}{|l|l|l|l|l|l|}
\hline \multirow{2}{*}{$\begin{array}{l}\text { The } \\
\text { granulumetries }\end{array}$} & \multicolumn{5}{|l|}{ The water/cement ratios } \\
\cline { 2 - 6 } & 0.50 & 0.55 & 0.60 & 0.65 & 0.70 \\
\hline A16-B16 & 3.65 & 2.90 & 2.71 & 2.40 & 1.70 \\
\hline B16 & 3.21 & 2.56 & 2.37 & 2.30 & 1.93 \\
\hline B16-C16 & 2.80 & 2.52 & 2.36 & 2.29 & 1.68 \\
\hline
\end{tabular}

\section{ANALYTICAL INVESTIGATION}

If one of the properties of the concrete such as the compressive strength, the tensile strength, the elasticity modulus only depends on the amount of the pores in the cement paste, the property of the concrete is insensitive to the pore structure of the cement paste. If the type (or the geometry) of the pores also specifies the property of the concrete, the property of the concrete is sensitive to the pore structure of the cement paste [5]. Therefore, calculating the correlation coefficients of the properties are useful to understand whether the property is sensitive or not sensitive to the pore structure of the cement paste.

If $\mathrm{P}_{\mathrm{fi}}$ is one of the properties of the fresh concrete such as the slump and $n_{i}$ is a parameter, the values of ni are calculated with the obtained values of $\mathrm{P}_{\mathrm{fi}}$ from the experiments according to the formulation;

$$
n_{i} \cdot w+a
$$

w: the amount of water in the fresh concrete

a: the percentage of the air voids

$\mathrm{n}_{\mathrm{i}}=\mathrm{n}_{\mathrm{i}}{ }^{*}$, the maximum correlation coefficient is calculated. In the Fig.3, the y-axis shows the values of Pfi which is obtained from the experiments, on the other hand the $\mathrm{x}$-axis shows the values of $\left(n_{i} \cdot w+a\right)$ which are calculated according to the values of $\mathrm{P}_{\mathrm{fi}}$. The graphic is drawn according to these values and then the peak point of the graphic is accepted as the maximum correlation coefficient of the property of the fresh concrete. Actually, after the graphic is drawn in Excel, the regration coefficient is found in the tendency of the graphic in Excel and then the square root of the regration coefficient of the graphic $\left(\sqrt{R^{2}}\right)$ is accepted as the maximum correlation coefficient (ni*).

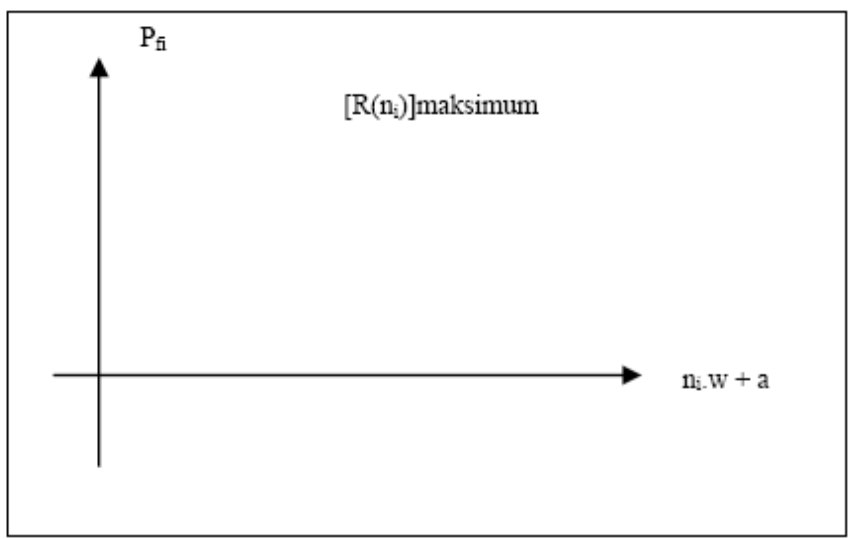

Fig.3-The relationship between $\mathrm{P}_{\mathrm{fi}}$ the property of the fresh concrete and $n_{i} \cdot w+a$
If $n_{i}^{*}=1$ The property is insensitive to the pore structure of the cement paste

If $n_{i}^{*} \neq 1$ The property is sensitive to the pore structure of the cement paste

Whether if the properties of the hardened concrete is sensitive or not, $n_{i} \cdot(w-1,06 . \alpha . c)+a$ is used instead of $n_{i} \cdot w$ $+a$ to consider the hydration of the cement paste. $w$ is the amount of the water in the concrete, $\alpha$ is the degree of the hydration, $c$ is the amount of the cement and $a$ is the percentage of the air voids in the concrete. The same processes are done to calculate the maximum correlation coefficient of the property of the hardened concrete.

Another way of calculating the maximum correlation coefficient is comparing with the unit weight of the concrete. The degree of the hydration is hard to be found so an approximate method should be used. The dry unit weight of the concrete is calculated in the experiments. The unit weight is insensitive to the pore structure of the cement paste since the effect of the pores on the unit weight is just related to the volume of the pores, not the geometry and the dimension so ni* is 1 for the unit weight. Therefore,

$\mathrm{n}_{\mathrm{i}} \cdot(\mathrm{w}-1,06 \cdot \alpha \cdot \mathrm{c})+\mathrm{a} \rightarrow(1-1,06 \cdot \alpha \cdot \mathrm{c} / \mathrm{w}) \cdot \mathrm{w}+\mathrm{a}$.

However, it is hard to calculate the correlation coefficients with these variants so the formulation is simplified as $\mathrm{k} . \mathrm{w}+$ a. The sensitivity of the unit weight should be investigated according to this formulation and the maximum correlation coefficient $(\mathrm{k}=\mathrm{ko})$ of the unit weight is calculated. Moreover, $(\mathrm{k} . \mathrm{w}+\mathrm{a})$ is used to investigate the sensitivity of a property of the hardened concrete and then a maximum correlation coefficient of the property of the hardened cement $\left(\mathrm{k}=\mathrm{ki}^{*}\right)$ is calculated. Here, ko and $\mathrm{ki}^{*}$ are accepted as the central tendency parameters. The relationship between ko and $\mathrm{ki}^{*}$ determines the sensitivity of the property of the hardened concrete compared to the sensitivity of the dry unit weight.

If $\mathrm{ko}=\mathrm{ki} *$ The property is affected by the pore structure of the cement paste like the dry unit weight so the property is insensitive.

If $\mathrm{ko} \neq \mathrm{ki}^{*}$ The property is sensitive.

When the first type degree of the sensitvity of one of the property of the hardened concrete to the pore structure of the cement paste (SD1)i is investigated, the ratio of $\mathrm{ki}^{*}$ and ko is calculated

$(\mathrm{SD} 1) \mathrm{i}=\mathrm{ki} * / \mathrm{ko}$

(SD1)i is close to the sensitivity coefficient, ni*.When the second type degree of the sensitvity of one of the property of the hardened concrete to the pore structure of the cement paste (SD2)i is investigated, the ratio of $\mathrm{R}\left(\mathrm{ki}^{*}\right)$ and $\mathrm{Ri}(\mathrm{ko})$ is calculated.

$(\mathrm{SD} 2) \mathrm{i}=\mathrm{R}\left(\mathrm{ki}^{*}\right) / \mathrm{R}(\mathrm{ko})$ 
Here, $\mathrm{R}\left(\mathrm{ki}^{*}\right)$ is the maximum correlation coefficient for the property of the hardened concrete which is calculated from $\mathrm{k} . \mathrm{w}+\mathrm{a} . \mathrm{R}(\mathrm{ko})$ is the maximum correlation of the property of the hardened concrete by using ko (the maximum correlation coefficient of the dry unit weight) instead of $\mathrm{k}$ in $\mathrm{k} . \mathrm{w}+\mathrm{a}$. The second type degree of the sensitivity is not more affected by the function of the iner structure so it is necessary to research the correlations between the properties in order to understand whether the secon type degree is significant or not. There are other relationships of the similarity of the different sides between the correlations and the properties. The above formulation helps to understand the other relationships [6].

$\left(\mathrm{P}_{\mathrm{hi}}\right)^{\prime}=\mathrm{A}(\mathrm{c}+\mathrm{w}+\mathrm{a})^{\prime}+\mathrm{B}(\mathrm{c} / \mathrm{k} \cdot \mathrm{w}+\mathrm{a})^{\prime}+\mathrm{C}(\mathrm{m})^{\prime}+\mathrm{D}$

Here ( )' are the ratio of the average in the serie of the variants in the paranthesis and how Phi, the property of the hardened cement is affected by relatively changes in the volume of the cement paste $(c+w+a)$, the structure of the cement paste $(\mathrm{c} / \mathrm{k} \cdot \mathrm{w}+\mathrm{a})$ and the granulumetry of the aggregates $(\mathrm{m})$. By using the results obtained from the tests, according to the formulations $\mathrm{A}(\mathrm{k} \cdot \mathrm{w}+\mathrm{a})+\mathrm{B}, \mathrm{A}(\mathrm{c} / \mathrm{k} \cdot \mathrm{w}+\mathrm{a})$ $+\mathrm{B}, \mathrm{A}(\mathrm{c}+\mathrm{w}+\mathrm{a})+\mathrm{B}(\mathrm{c} / \mathrm{k} \cdot \mathrm{w}+\mathrm{a})+\mathrm{C}$ and $\mathrm{A}(\mathrm{c}+\mathrm{w}+\mathrm{a})+$ $\mathrm{B}(\mathrm{c} / \mathrm{k} \cdot \mathrm{w}+\mathrm{a})+\mathrm{C}(\mathrm{m})+\mathrm{D}$, the correlation coefficients of the properties of the hardened concrete are calculated for every formulations.

In Table 2-5, the correlation coefficients of some properties of the concrete obtained from the formulations are seen.

Table 2 - ki*, (SD1)i, R(ki*), R(ko) and (SD2)i of the properties according to $\mathrm{A}(\mathrm{k} \cdot \mathrm{w}+\mathrm{a})+\mathrm{B}$

\begin{tabular}{|l|l|l|l|l|l|}
\hline Property & $\mathrm{ki}^{*}$ & $(\mathrm{SD} 1) \mathrm{i}$ & $\mathrm{R}\left(\mathrm{ki}^{*}\right)$ & $\mathrm{R}(\mathrm{ko})$ & $(\mathrm{SD} 2) \mathrm{i}$ \\
\hline $\begin{array}{l}\text { Cylinder } \\
\text { Compressive } \\
\text { Strength }\end{array}$ & 1,04 & 0,301 & 0,9715 & 0,9321 & 1,04 \\
\hline Dry unit weight & 3,46 & 1,000 & 0,8924 & 0,8924 & 1,00 \\
\hline Splitting Strength & 0,99 & 0,286 & 0,8150 & 0,7758 & 1,05 \\
\hline Brittleness Index & 1,38 & 0,399 & 0,9347 & 0,9192 & 1,02 \\
\hline Elasticity Modulus & 1,35 & 0,390 & 0,9322 & 0,9154 & 1,02 \\
\hline
\end{tabular}

Table 3 - ki*, (SD1)i, R(ki*), R(ko) and (SD2)i of the properties according to $\mathrm{A}(\mathrm{c} / \mathrm{k} \cdot \mathrm{w}+\mathrm{a})+\mathrm{B}$

\begin{tabular}{|l|c|c|c|c|c|}
\hline Property & $\mathrm{ki}^{*}$ & $(\mathrm{SD} 1) \mathrm{i}$ & $\mathrm{R}\left(\mathrm{ki}^{*}\right)$ & $\mathrm{R}(\mathrm{ko})$ & $(\mathrm{SD} 2) \mathrm{i}$ \\
\hline $\begin{array}{l}\text { Cylinder } \\
\text { Compressive } \\
\text { Strength }\end{array}$ & 1,78 & 0,121 & 0,9634 & 0,9203 & 1,05 \\
\hline Dry unit weight & 1,14 & 1,000 & 0,8766 & 0,8766 & 1,00 \\
\hline $\begin{array}{l}\text { Splitting } \\
\text { Strength }\end{array}$ & 1,33 & 0,117 & 0,7987 & 0,7605 & 1,05 \\
\hline Brittleness Index & 2,05 & 0,180 & 0,9266 & 0,9102 & 1,02 \\
\hline $\begin{array}{l}\text { Elasticity } \\
\text { Modulus }\end{array}$ & 1,95 & 0,171 & 0,9208 & 0,9022 & 1,02 \\
\hline
\end{tabular}

Table 4 - ki*, (SD1)i, R(ki*), R(ko) and (SD2)i of the properties according to

\begin{tabular}{|l|l|l|l|l|l|}
\hline \multicolumn{7}{|c|}{$\mathrm{A}(\mathrm{c}+\mathrm{w}+\mathrm{a})+\mathrm{B}(\mathrm{c} / \mathrm{k} \cdot \mathrm{w}+\mathrm{a})+\mathrm{C}$} \\
\hline Property & $\mathrm{ki}^{*}$ & $(\mathrm{SD} 1) \mathrm{i}$ & $\mathrm{R}\left(\mathrm{ki}^{*}\right)$ & $\mathrm{R}(\mathrm{ko})$ & $(\mathrm{SD} 2) \mathrm{i}$ \\
\hline $\begin{array}{l}\text { Cylinder } \\
\text { Compressive } \\
\text { Strength }\end{array}$ & 1,85 & 1,58 & 0,9747 & 0,9716 & 1,003 \\
\hline $\begin{array}{l}\text { Dry unit } \\
\text { weight }\end{array}$ & 1,17 & 1,00 & 0,9145 & 0,9145 & 1,000 \\
\hline $\begin{array}{l}\text { Splitting } \\
\text { Strength }\end{array}$ & 1,68 & 1,44 & 0,8313 & 0,8170 & 1,018 \\
\hline $\begin{array}{l}\text { Brittleness } \\
\text { Index }\end{array}$ & 1,32 & 1,13 & 0,9438 & 0,9432 & 1,001 \\
\hline $\begin{array}{l}\text { Elasticity } \\
\text { Modulus }\end{array}$ & 1,34 & 1,15 & 0,9369 & 0,9362 & 1,001 \\
\hline
\end{tabular}

Table 5 - ki*, (SD1)i, R(ki*), R(ko) and (SD2)i of the properties according to

$\mathrm{A}(\mathrm{c}+\mathrm{w}+\mathrm{a})+\mathrm{B}(\mathrm{c} / \mathrm{k} \cdot \mathrm{w}+\mathrm{a})+\mathrm{C}(\mathrm{m})+\mathrm{D}$

\begin{tabular}{|l|l|l|l|l|l|}
\hline Property & $\mathrm{ki}^{*}$ & $(\mathrm{SD} 1) \mathrm{i}$ & $\mathrm{R}\left(\mathrm{ki}{ }^{*}\right)$ & $\mathrm{R}(\mathrm{ko})$ & $(\mathrm{SD} 2) \mathrm{i}$ \\
\hline $\begin{array}{l}\text { Cylinder } \\
\text { Compressive } \\
\text { Strength }\end{array}$ & 1,29 & 0,816 & 0,9763 & 0,9761 & 1,000 \\
\hline Dry unit weight & 1,58 & 1,000 & 0,9379 & 0,9379 & 1,000 \\
\hline $\begin{array}{l}\text { Splitting } \\
\text { Strength }\end{array}$ & 0,20 & 0,127 & 0,9632 & 0,9010 & 1,069 \\
\hline $\begin{array}{l}\text { Brittleness } \\
\text { Index }\end{array}$ & 1,18 & 0,747 & 0,9442 & 0,9417 & 1,003 \\
\hline $\begin{array}{l}\text { Elasticity } \\
\text { Modulus }\end{array}$ & 1,43 & 0,905 & 0,9371 & 0,9368 & 1,000 \\
\hline
\end{tabular}

\section{CONCLUSIONS}

With the increasing water/cement ratio, the dry unit weight, the splitting and the compressive strengths, the brittleness index and the elasticity modulus decrease. The granulumetric composition of the aggregate does not pratically effect the unit weight and the brittleness index. When the compressive strength increases, the brittleness index and the ratio between the compressive strength and the splitting strength rises. The fact reveals that when the strength increases, the concrete becomes brittle. The correlations between the properties are strong because the sensitivity of the properties to the pore structure of the cement paste is similar. However, if the variants increase in the formulations, the sensitivity to the pore structrure of the cement paste is veiled. When comparing the results of these formulas, (SD1)i values differ for every formulation and the distribution of (SD2)i values are less. Therefore, the second type sensitivity coefficients represent the sensitivity of the properties of the concrete to the structure of the cement paste more than the first type sensitivity coefficients. Formulation (5) is the most reliable to represent the sensitivity of the properties of the concrete to the structure of the cement paste. 


\section{REFERENCES}

[1]. Brandt, A.M., 1999, Cement and Other Binders, Cement Based Composites, Materials Mechanical Properties and Performance, pp 47-52, London.

[2]. Diamond, S., 1995, Microstructure of Cement Based Materials/Bonding and Interfaces in Cementitious Materials, Materials Research Center, Vol: 370.

[3]. Zimbelmann, R., 1989, A Contribution to The Problem of Cement-Aggregate Bond, Cement and Concrete Research, 15, pp 801-808.

[4]. Mehta, P.K. qnd Aitcin, P.C., 1990, Microstructural Basis of Selection of Materials and Mix Proportions for High Strength Concrete, 2nd International Symposium onHigh Strength Concrete, pp 265-285, Berkeley, California.

[5]. Oktar,O.N., Moral,H. and Tasdemir,M.A.,1984, Sensitivity of Concrete Properties to The Pore Structure of Hardened Cement Paste,Cement and Concrete Research,Vol26,No:11,1619-1627,Istanbul

[6]. Oktar,O.N., Moral,H, and Tasdemir,M.A.,1984,Factors Determining The Correlations Between Concrete Research,Vol 26 No:11,1619-1627,Istanbul. 